\title{
Shock-elicited attack and biting as a function of chronic vs. acute insulin injection
}

\author{
STEPHEN F. DAVIS, ELAINE L. CRONIN, and JERRY A. MERIWETHER \\ Austin Peay State University, Clarksville, Tennessee 37040 \\ JERRY NEIDEFFER \\ Tarrant County Medical Education and Research Foundation, Fort Worth, Texas 76117
}

and

\author{
MARY NELL TRAVIS-NEIDEFFER \\ Texas Christian University, Fort Worth, Texas 76129
}

\begin{abstract}
Two experiments investigating the effects of chronic vs. acute insulin-induced hypoglycemia on attack and biting behavior elicited by tailshock are reported. Chronic-injection subjects had blood-sugar level experimentally reduced by insulin for 29 days, including the day of shock testing. Acute-injection subjects received an insulin injection only on the day of testing. High levels of attack and biting behavior were shown in the single-animal shock-elicited aggression situation by the chronic subjects in both experiments. High response levels were shown by the acute-injection subjects only in Experiment 2. The lack of such responding in Experiment 1 was attributed to the different injection procedures used in the two experiments. The data are supportive of the proposed negative relationship between hypoglycemia and aggressive responding.
\end{abstract}

A recent series of experiments conducted in our laboratory (Davis, Gussetto, Tramill, Neideffer, \& Travis-Neideffer, in press; Neideffer, Travis, Davis, Voorhees, \& Prytula, 1977) has sought to experimentally verify a functional relationship between blood-sugar level and aggressive responding. Based upon field studies reported by Bolton (see Bolton, 1973, 1976; Bolton \& Vadheim, 1973), it has been proposed that blood-sugar level and aggression are negatively related. Generally speaking, our data have been quite supportive of this relationship.

The procedure employed in the Davis et al. (in press) and Neideffer et al. (1977) studies has been to administer a single subcutaneous injection of regular zinc insulin and then test the animals (rats) $1 \mathrm{~h}$ later in the single-animal, shock-elicited aggression situation. Convincing as the results of these studies may be, it is also possible that they do not mirror the "real" state of affairs very accurately, even for an animal subject. Most organisms suffering from hypoglycemia (low bloodsugar level) do not experience only one drop in glucose level, as did the subjects in these experiments. Therefore, it seemed appiopriate to question whether or not the relationship observed under the single-injection

This research was supported in part by a Tower Fund Research Grant from Austin Peay State University to the first author. Portions of this paper were presented at the annual meeting of the Southern Society for Philosophy and Psychology, 1978. condition would also be observed when several such decreases in blood-sugar level had been experienced.

\section{EXPERIMENT 1}

The purpose of Experiment 1 was to evaluate the effects of chronic or repeated insulin injections (i.e., multiple drops in blood-sugar level) on attack and biting behavior. An injection-control group receiving repeated injections of Phenol (the carrier used in insulin preparations) was included to evaluate cumulative injection effects. The repeated or "chronic" groups were evaluated relative to single-injection ("acute") insulin and Phenol groups receiving an injection only on the day of testing.

\section{Method}

Subjects. Twenty-eight naive male rats purchased from the Holtzman Company, Madison, Wisconsin, served as subjects. The animals were approximately 90 days old upon arrival at the laboratory. For the duration of the experiment, all subjects were individually caged with food and water freely available.

Apparatus. Testing took place in a shock-elicited aggression apparatus (more fully described in Mollenhour, Voorhees, \& Davis, 1977) consisting of an opaque restraint tube, shock source, target rod (Lafayette Instrument Company, Model 80111, omnidirectional lever), and impulse counter. Attack upon the target rod, which extended across the midportion of the open end of the restraint tube, activated the impulse counter, thus yielding an automated record of the number of responses made by each subject. The subject's tail was extended through a $1.50-\mathrm{cm}$ hole in the closed end of the restraint tube. Once a subject was in place in the restraint tube, 
a wood rod was secured to the tail by means of adhesive tape, thus prohibiting escape during shock testing. Two copper wires, permanently attached to the wood rod $7.00 \mathrm{~cm}$ apart, served as electrodes for the administration of tailshock.

Procedure. Upon receipt from the supplier, the subjects were randomly distributed to four equal groups $(n=7)$. Subjects in the chronic-insulin (C-I) and chronic-Phenol (C-P) groups received two 6-unit subcutaneous injections of regular $\mathrm{U}-40$ zinc insulin (regular Iletin, Eli Lilly \& Company) and $.06 \%$ Phenol, respectively, each day for 29 days. The last day of injection for these groups was also the day of shock testing. Subjects in the acute-insulin (A-I) and acute-Phenol (A-P) groups received the two,6-unit injections of insulin and Phenol, respectively, only on the day of testing. In all cases the two daily injections were separated by a 12-h period.

On the day of testing, each subject was individually tested $1 \mathrm{~h}$ after receiving the second injection. Following a 5-min habituation period in the restraint tube, a $1.50-\mathrm{mA}$ shock of $300-\mathrm{msec}$ duration was applied every $3 \mathrm{sec}$ for $10 \mathrm{~min}$. The number of target-directed responses was recorded for each subject.

\section{Results and Discussion}

Prior to analysis, the response total for each subject was converted to a $\log _{10}\left(\mathrm{X}_{\mathrm{i}}+1\right)$ score. Group mean attack and biting scores are shown in Figure 1. A significant Acute-Chronic by Insulin-Phenol interaction $[F(1,24)=4.33, p<.05]$ was yielded by analysis of variance. Simple main effects analyses of variance indicated that Group C-I responded significantly more than Groups A-I $[\mathrm{F}(1,24)=4.53, \mathrm{p}<.05]$ and C-P $[F(1,24)=4.49, p<.05]$. Thus, the statistical analyses are supportive of the graphical impression that repeated insulin injections did not result in lowered responding.

Subject weights were recorded daily. Comparisons ( $\mathrm{F}_{\max }$ and one-way analysis of variance) of this weight data were performed on randomly selected days during the 28 days preceding testing and the test day itself. As no significant differences were yielded by any of these analyses, the possibility of any weight-drug confounding appears unlikely.

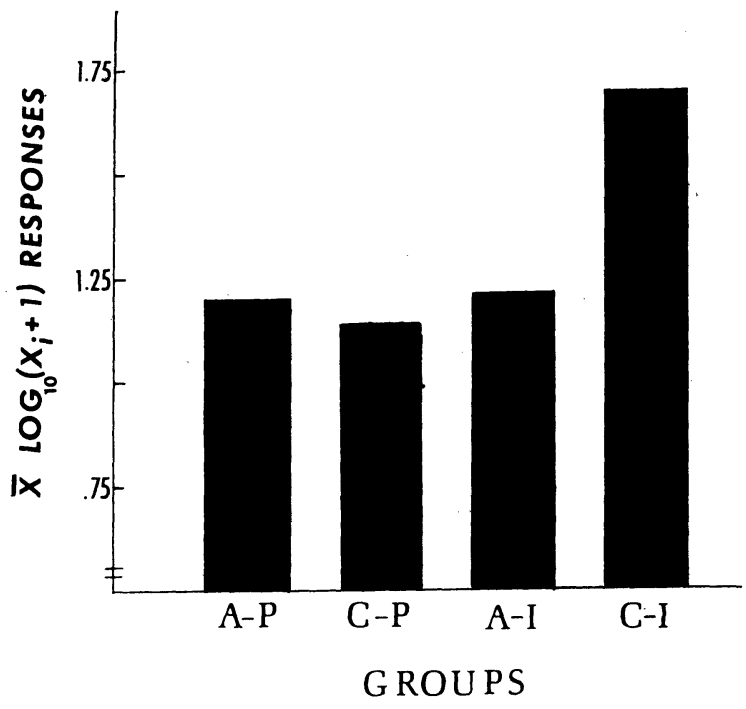

Figure 1. Group mean responses, Experiment 1.
In view of the previous data, the rather low response level shown by Group A-I was somewhat unexpected. Also, it was noticed that the majority of the responses emitted by subjects in Group C-P occurred during the initial portions of the testing situation. As this effect was not noticed in the acute-Phenol subjects, the possibility of some debilitation due to the repeated injection of Phenol was suggested. These questions were directly addressed in Experiment 2.

\section{EXPERIMENT 2}

In the second experiment, acute- and chronicinjection procedures were again employed. However, only one daily injection was administered. The performance of Group A-I (Experiment 1) prompted this change in procedure. As this group had received two 6-unit injections separated by $12 \mathrm{~h}$, the effects of the first injection may have dissipated by the time the second injection was administered. Thus, the functional dosage for this group could easily have been 6 units instead of 12. This being the case, the Neideffer et al. (1977) data would lead one to predict the lowered level of responding that was observed. The use of a single 12-unit injection should result in an increase in attack and biting.

Chronic- and acute-injection control groups receiving distilled water injections were employed in Experiment 2 in order to evaluate possible debilitating effects of Phenol. Thus, six groups of subjects (two acute and two chronic) were tested following insulin, Phenol, and distilled water injections, respectively, in Experiment 2.

\section{Method}

Subjects. Forty-two 90-day-old male albino rats purchased from the Holtzman Company, Madison, Wisconsin, served as subjects. Housing and feeding conditions were similar to those of Experiment 1.

Apparatus. The apparatus used in Experiment 1 was used in Experiment 2.

Procedure. Upon arrival at the laboratory, the subjects were randomly distributed across six equal groups $(n=7)$. Subjects in the chronic-insulin (C-I), chronic-Phenol (C-P), and chronic distilled water (C-DW) groups received one 12-unit subcutaneous injection of U-40 regular zinc insulin (regular Iletin, Eli Lilly \& Company), .06\% Phenol, and distilled water, respectively, for 29 days including the day of testing. Subjects in the acute-insulin (A-I), acute-Phenol (A-P), and acute distilled water (A-DW) groups received a single injection of insulin, Phenol, and distilled water, respectively, only on the day of testing. Testing procedures were similar to those used in Experiment 1 .

\section{Results and Discussion}

As in Experiment 1, all responses were converted to $\log _{10}\left(X_{i}+1\right)$ scores prior to analysis. Group means are shown in Figure 2. Analysis of variance yielded a significant $[F(2,36)=9.41, p<.01]$ drug effect. NewmanKeuls tests indicated that the Phenol and distilled water treatments did not differ from each other, but 


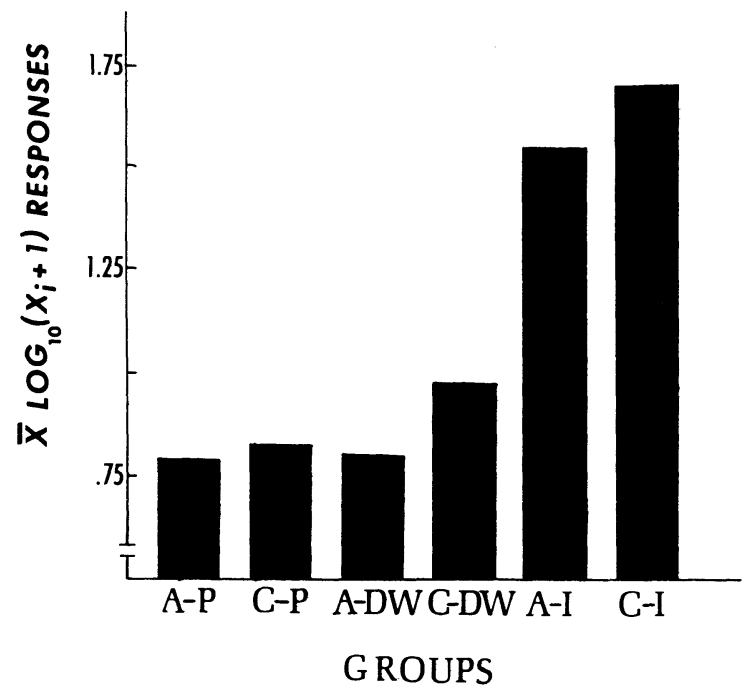

Figure 2. Group mean responses, Experiment 2.

were significantly $(p<.01)$ lower than the insulin treatment. Weights were recorded and analyzed as in Experiment 1. As no significant effects were found, the possibility of weight-drug confounding again appears quite unlikely.

The high level of responding shown by Group $\mathrm{C}-\mathrm{I}$ in Experiment 2 compliments that shown by the comparable group in Experiment 1. These high response levels indicate that adaptation to the repeated lowering of blood-sugar level did not occur.

The high level of responding shown by the A-I subjects in Experiment 2 is certainly in agreement with the data reported by Davis et al. (in press) and Neideffer et al. (1977). It seems reasonable to attribute the lower level of performance shown by the A-I subjects in Experiment 1 to the difference in injection procedure used in the two experiments.
Unlike Experiment 1, the chronic-Phenol subjects in Experiment 2 did not appear to confine their responding to the initial portions of the test session. Thus, the concern over possible debilitation due to chronic Phenol injection raised by Experiment 1 may have been due simply to chance or it may have been an artifact created by the particular injection procedure used.

The results of these two studies lend additional experimental support to the proposed negative relationship between blood-sugar level and aggressive responding. The picture that is beginning to emerge from this program of research is one of a rather robust phenomenon certainly deserving of further refinement and attention.

\section{REFERENCES}

Bolton, R. Aggression and hypoglycemia among the Qolla: A study in psychobiological anthropology. Ethnology, 1973, 12, 227-257.

Bolton, R. Hostility in fantasy: A further test of the hypoglycemiaaggression hypothesis. Aggressive Behavior, 1976, 2, 257-274.

Bolton, R., \& VAdheim, C. The ecology of East African homicide. Behavior Science Notes, 1973, 8, 319-341.

Davis, S. F., Gussetto, J. K., Tramill, J. L., Neideffer, J., \& Travis-NeIDEFFer, M. N. The effects of extended insulin dosage on target-directed attack and biting elicited by tailshock. Bulletin of the Psychonomic Society, in press.

Mollenhour, M. N., Voorhees, J. W., \& Davis, S. F. Sleepy and hostile: The effects of REM sleep deprivation on shockelicited aggression. Animal Learning \& Behavior, 1977, 5, 148-152.

Neideffer, J., Travis, M. N., Davis, S. F., Voorhees, J. W., \& PrYtula, R. E. Sweet and sour rats: The effect of insulin dosage on shock-elicited aggression. Bulletin of the Psychonomic Society, 1977, 10, 311-312.

(Received for publication May 5, 1978.) 